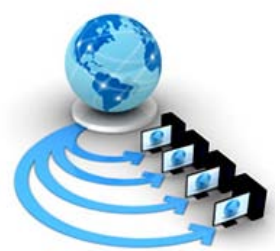

Volume 9, No. 2, March-April 2018

International Journal of Advanced Research in Computer Science

RESEARCH PAPER

\title{
SMART APPLICATION FOR POST ACCIDENT MANAGEMENT USING IOT
}

\author{
Prof. Amit Gadekar \\ Department of Computer Engineering, \\ Sandip Institute of Technology and Research Centre, \\ Sandip Foundation, Nasik, India.
}

Atul More

Department of Computer Engineering,

Sandip Institute of Technology and Research Centre, Sandip Foundation, Nashik, India

\author{
Shubham Patil \\ Department of Computer Engineering, \\ Sandip Institute of Technology and Research Centre, \\ Sandip Foundation, Nashik, India. \\ Sachin Hiray \\ Department of Computer Engineering, \\ Sandip Institute of Technology and Research Centre, \\ Sandip Foundation, Nashik, India
}

\begin{abstract}
The situation in India about road accidents is a serious problem. The State and Central government have been implementing measures to prevent the accidents on road by making helmets compulsory for two wheelers, speed limits, banning drivers from using mobile phones,etc. But if the accident occurs there is no provision for the victims to get the medical assistance immediately. So, accidents are the considerable economic losses to victims, their families, and to countries as a whole. To help the victims of road side accidents an android application will be developed. The witness of an accident can help the victim by just sending the image of that accident spot to nearby hospital or ambulance and nearby police station for further inquiry. A provision can also be made in future to get the identity of the victim to inform his/her relatives, this can either be done by matching the captured image of the victim with Aadhar card linked database or by bio-metrics. The main goal behind the development of our app will be to save the victim's life, as soon as any witness have noted the accident spot or whoever had notice such an incident.
\end{abstract}

Keywords: Victim Image, Location Coordinates, Android Application, Ambulance.

\section{INTRODUCTION}

As worldwide, Road accidents is serious issue and challenges. India is committed to reduce the number of road accidents and fatalities by 50 percent by 2020. However, with one of the highest motorization growth rate in the world accompanied by rapid expansion in road network and urbanization over the years, our country is faced with serious impacts on road safety levels. The Government of India record says that, 1,374 accidents take place in one day on Indian roads, which leads to 400 deaths. The further analysis of this data says that for every hour there is a loss of 17 lives on an average in our country.

To decrease this problem, a robust accident detection and alert system need to be developed to accurately detect the accident and apply further necessary action. After accident immediate one hour plays crucial role. Generally after accident, people lose their lives due to many reasons. One of them is lack of emergency services. We are commited to develop an app in such a way that it will not only detect accident coordinates, but will also provide alert messages to registered ambulance service providers with no time lag. The main goal behind to send image of accident spot is to detect genuine accident, as time and date will also be recorded along with image from user's device.

In response to successfully prevent death of victim, our system also make sure that hospital is aware of ambulance reporting to their place. We have developed a dedicated web application to display necessary details. Our system also display users
Identification details to police authority in case of critical accident case. We found following traditional way to report accident.

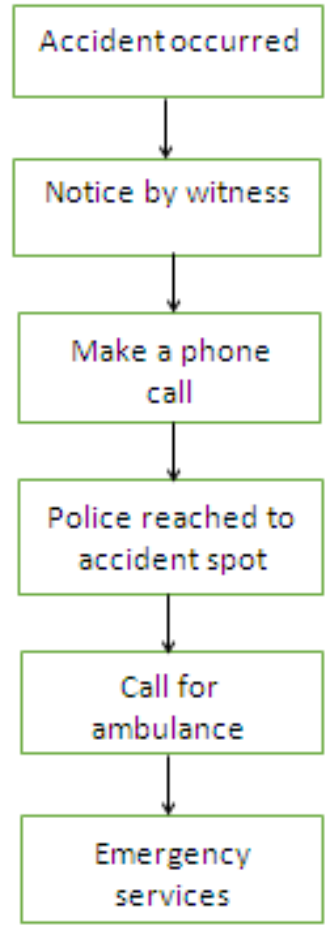


Our approach to solve above problem.

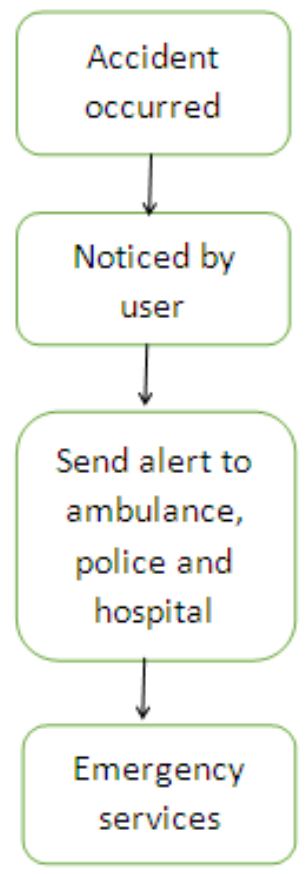

\section{REVIEW OF LITERATURE}

[1] Hrishikesh Murkut, Fazal Patil, Vishal Yadav, Meghana Deshpande proposed a automatic accident detection and rescue with ambulance system. The system consists of dedicated vehicle unit, which works on vibration sensors. Vibration sensors sense the unusual activity while driving and then report to microcontroller unit. Location coordinates are obtained through GPS. We found that there is need to put geographical location coordinates manually in GPS viewer application.

[2]proposed mobile application for automatic accident detection and multimodal alert system, using global positioning system receiver, radio frequency modules and a field programmable gate array. The system consists of PHY layer and universal serial bus connections for implementations.

[3] The author of third paper proposed intelligent accident detection system, in which they have used GSM unit which is fitted in the vehicle. The GSM unit detects accident and sends the location to main server. The main server has all the records of nearest hospitals. Drawback of this system is that, If GSM unit in the vehicle gets damaged due to accident, the whole system collapse.

[4] The author of this paper suggested detection of accident using image processing. The system comprises of CCD camera which is used to extract the accident vehicles from the video image. It used the concept of velocity and its variation rate, position area. The drawback of proposed system is that, the position of video camera is fixed at particular location. We cannot predict the accident at remote location.

[5] In this paper, the author had deployed sensor (i.e. heart beat sensor) which is integrated with mobile technology such as android. The system analyze the signal from heart beat sensor and filter out background noise, detects only the sound of pulse. Detection of accident is identified from the variation of normal heart beat rate. If accident is detected successfully, the system will transmit the location coordinates to the pre-configured contacts with the help of short message service.

[6] The author of this paper had presented cloud based solution to detect accidents and monitor data accordingly. The system works on sensor based approach, which transmits data to microcontroller present in the vehicle. Further, according to position of vehicle latitude and longitude values are compute by GSM device installed in the vehicle. Alert message will be send to registered mobile number which owner of the device has provided earlier. The device's software and cloud is used to log data and real time storage.

[7] According to author, the system called, vehicle accident detection is divided into two phases. The detection phase and the notification phase. Smartphone accelerometer sensor is used to sense the accident condition and GPS receiver deployed continuously extracts data determining vehicle travel speed. The algorithm uses variation in vehicle speed as a major parameter for detecting accidents based on accelerometer sensor data.

[8] In this, author had used client server model for detection of car accidents and provide awareness of situation to emergency service responders. The system consists of cell-phone sensors such as accelerometer to detect the accident. User part consists of accident detection, multimedia upload, accident mapping and contact registration. Server operations consists of data aggregation, emergency dispatch, map and data hosting, contact notification. The system displays information to users through web interface. Drawback of this model is, in case of serious accident the phone may get destroyed resulting into disconnection of emergency responders.

[9] In this paper, the author had developed an android application which send request to the server. The android application monitors users health parameters such as ECG, sugar and BP. Server sends data to ambulance and hospital which contains latitude and longitude values, call information and status. The system provides continuous monitoring facility through connectivity from ambulance to hospital.

\section{SYSTEM OVERVIEW}

\section{A.Problem Statement}

In emergency situations, even a 10 to 12 minutes delay in the arrival of ambulance may mean death! More than 70 times out of 100 , calls made by phone, lack to provide exact location. To circumvent this problem we are going to developed an application that will help to reduce response time after accident. It does this by informing nearest available ambulance service with location details.

\section{B. Proposed System Architecture}

The proposed system consists of four main units depending on their functional and behavioral implementations, which coordinates with each other and makes sure that that ambulance reaches the accident spot without any time lag. Thus our system is divided into following four units:

1. The User Unit

2. The System Unit

3. The Hospital Unit

4. The Police Unit 
User Unit:According to our system design, registration of user is mandatory to prevent fake accident detection. On detection of accident, user will capture image and upload it through our android application. Additional information such as vehicle number, document details, etc. are also provided to detect identity of victim. The main function of this unit is to detect accident, capture image of accident place and upload it to our application.Input from user unit is provided to our system which will attach location coordinates through GPS and detect the nearest possible ambulance.

System Unit:Input from user unit is passed to system, which fetch location coordinates of user. The main function of system unit is to detect accident location and registered emergency responders i.e. ambulance which is nearer and quickly available from accident location. Once system detects the status of ambulance as available, it will send alert messages. System unit will also send notifications to Hospital and Police unit too.

Hospital Unit: Hospital will receive message from system. Data will be displayed through web application which will contain image, location of accident and necessary details.

Police Unit:User in system will have choice to determine whether accident occurred in critical or normal. According to his judgement we will inform police authority. If accident is critical in nature, accordingly system will send message to police which will display location and identity details on web application.
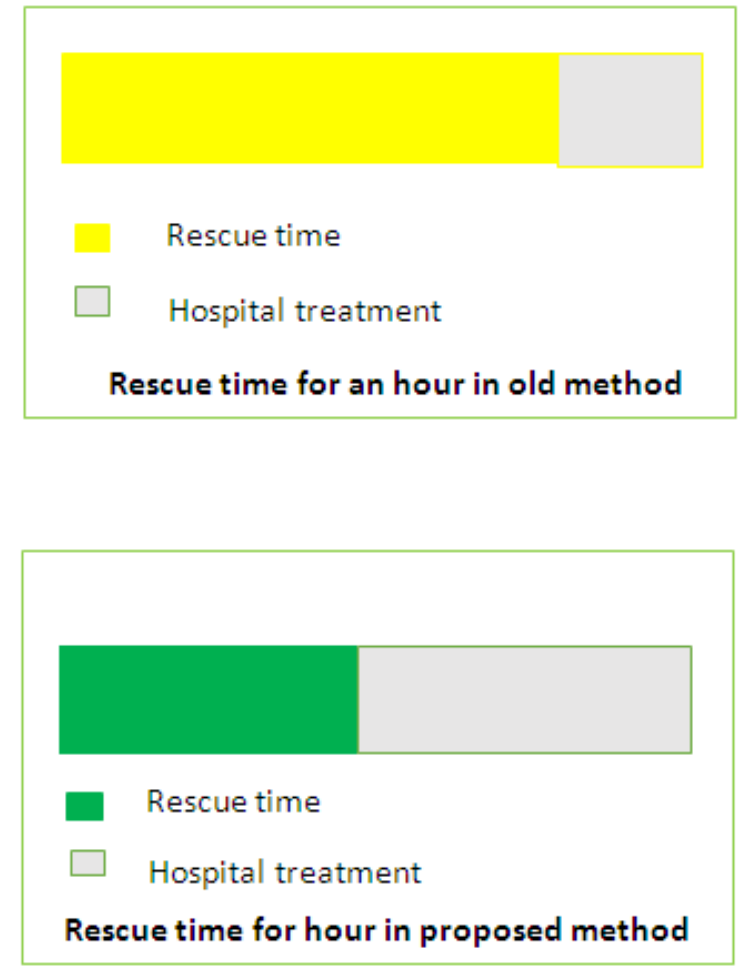

The architectural diagram of our system is as shown below,

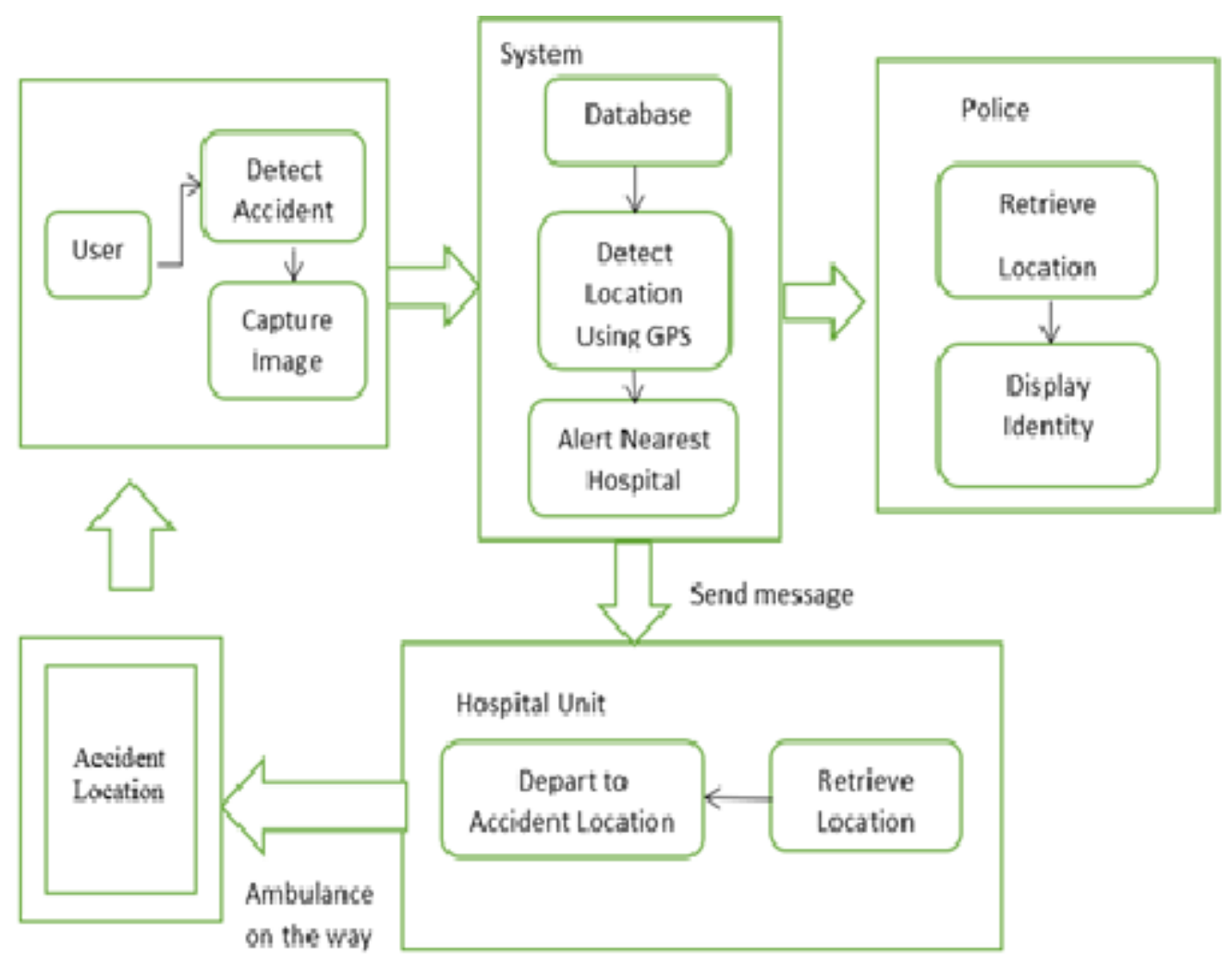




\section{MATHEMATICAL MODEL}

Let $\mathrm{S}$ contains the set of attributes required for detection of accident location.

computation of recommendation algorithm.

$\mathrm{S}=\{\mathrm{U}, \mathrm{I}, \mathrm{O}, \mathrm{F}\}$

$\mathrm{U}=\{\mathrm{U} 1, \mathrm{U} 2, \mathrm{U} 3, \ldots \mathrm{Un}\}$

$\mathrm{U}$ is a set of users

$\mathrm{n}$ - Number of users.

$\mathrm{I}=\{\mathrm{I} 1, \mathrm{I} 2, \mathrm{I} 3\}$

I is set of Inputs

I1 = Captured Image (required)

I2 = vehicle no.

I3 = Identity proof no.

$\mathrm{O}=\{\mathrm{O} 1, \mathrm{O} 2, \mathrm{O} 3\}$

$\mathrm{O}$ is a set of output

$\mathrm{O} 1$ = location to ambulance

$\mathrm{O} 2$ = alert to Hospital

O3 = location \& identity to Police

$F=\{F 1, F 2\}$

Function F1 (Un) $\rightarrow$ R

Function F1 checks whether user is registered or not

Function F2 (R) $\rightarrow$ ( L , S , A )

Function F2 detects location coordinates and send messages

$\mathrm{L}=$ detect location coordinates

$\mathrm{S}=$ send Image \& location to Ambulance

A = send Image and identity to Hospital, Police.

\section{CONCLUSION}

In this paper, a novel idea is proposed to detect accident and report it to emergency service, hospital and police with internet message. The proposed system will help a victim to get emergency services (i.e. ambulance) quickly after a accident is reported. The proposed system will work in such a manner, that it help to reduce response time and prevent any further time lag., which in turn will increase a probability of victim to save his life. This system can be effectively implemented for an metropolitan city or countries with large population like India.

\section{REFERENCES}

[1] Hrishikesh Murkut, Fazal Patil, Vishal Yadav, Meghana Deshpande "Automatic Accident Detection and Rescue with Ambulance”, SSRG International Journal of Electronics and Communication Engineering, 2015.

[2] Bruno Fernandes, Arnaldo S. R. Oliveira "Mobile Application for Automatic Accident Detection and Multimodal Alert", research gate may 2015.

[3] Bandari Prachi, Dalvi Kasturi, Chopade Priyanka "Intelligent Accident-Detection and AmbulanceRescue System”, International Journal of Scientific \& Technology Research, June 2014.

[4] Yong-Kul Ki "Accident Detection System using Image Processing and MDR”, International Journal of Computer Science and Network Security, March 2007.

[5] P. Kaladevi, T. kokila, S. Narmatha, V. Janani, "Accident Detection Using Android Smart Phone”, International Journal of Innovative Research in Computer and Communication Engineering, March 2014.

[6] Rahul Gautam, Shubham Choudhary, Surbhi, Inderjeet Kaur, Mamta Bhusry " Cloud BasedAutomatic Accident Detection and Vehicle Management System”, International Conference on Science, Technology and Management, 2015.

[7] Hamid M. Ali, Zainab S. Alwan “ Car Accident Detection and Notification System Using Smartphone”, International Journal of Computer science and Mobile Computing,2015

[8] Chris Thompson, Jules White, Brian Dougherty, Adam Albright, and Douglas C. Schmidt "Using Smartphone to Detect Car Accidents and Provide Situational Awareness to Emergency Responders".

[9] Hamilton Allen Turner, Douglas Schmidt, "WrechWatch: Automatic Traffic Accident Detection and Notification with Smartphones”, June 2011. 